Feedback from those who have completed the workbook indicates staff feel more competent in recognising and dealing with issues such as pain and symptom management but equally importantly, also feel empowered to access local supportive services.

\section{P-48 KIRKLEES CARE HOME CHAMPION PILOT}

${ }^{1}$ Sadaf Adnan, 'Jayne Bargh, 'Deborah Hanson, ${ }^{2}$ Bronwynn Bennett. ' Kirkwood Hospice, Huddersfield, UK; ${ }^{2}$ Kirklees Council, Huddersfield, UK

10.1136/bmjspcare-2019-HUKNC.72

The Kirklees and Calderdale End of Life Training and Education group were successful in a bid for West Yorkshire Excellence Centre funding in 2017, in order to develop targeted end of life care training and education across care homes in Kirklees and Calderdale.

A comprehensive workbook was developed and launched in October 2018, and was positively received by key stakeholders including the Care Quality Commission, Clinical Commissioning Groups, Kirklees Council and local care homes.

Locally, there is recognition that structured support is required with a focus on quality improvement in order to support nominated members of staff from care homes in improving end of life care delivery as well as embedding sustained change. This has been requested from care home managers in order to support how the workbook is aligned to day to day practice. This provides a real opportunity to ensure the delivery of the Kirklees End of Life vision and the national Ambitions Guidance within a care home setting.

A pilot of care home end of life champions is in development, in partnership with Kirklees Council. The first cohort will undertake six half-day sessions over a period of six months, covering:

- Advance care planning;

- Communication skills;

- Recognising and supporting someone who is dying;

- Spirituality and bereavement;

- Two Quality Improvement sessions.

Care home staff at HCA level across Kirklees will be upskilled, improving knowledge of key end of life care issues and concerns in order to better support patients in the last year of life.

Through key support staff benefiting from investment in training, quality improvement activity will also be undertaken in each home in order to support improvements in two of the following areas: Nutrition and hydration, Communication skills, falls prevention, and mouth care.

Through targeted education and support, Champions taking part in this exciting initiative will be encouraged to engage with local stakeholders to share best practice and evidence quality improvement activity.

\section{P-49 END OF LIFE CARE @ HOME: CARE ASSISTANT CERTIFICATE}

${ }^{1}$ Clare Lawrance, ${ }^{2}$ Carole Cousins, ${ }^{3}$ Sian Williams, ${ }^{4}$ Sara Stevenson-Baker, ${ }^{2} J a n e$ Berg. ${ }^{1}$ Woking and Sam Beare Hospices, Woking, UK; ${ }^{2}$ Princess Alice Hospice, Esher, UK; ${ }^{3}$ Phyllis Tuckwell Hospice, Farnham, UK; ${ }^{4}$ St Catherine's Hospice, Crawley, UK

10.1136/bmjspcare-2019-HUKNC.73
A collaborative educational initiative in Surrey aimed at care workers delivering end of life care at home.

National End of Life Care strategy strongly emphasises the need to provide excellent end of life care in all settings (Department of Health, 2008; National Palliative and End of Life Care Partnership, 2015; Hospice UK, 2017). However, current statistics indicate that while $80 \%$ of people would prefer to die at home, only $23.5 \%$ achieve this (Hospice UK, 2017; ONS, 2018).

A suggested contributory factor is the lack of appropriate expertise in end of life care within the domiciliary care setting. To address this need, the four Surrey hospices (Woking \& Sam Beare, Phyllis Tuckwell, Princess Alice and St Catherine's) developed a partnership with agency staff to co-design and introduce an end of life training course specifically aimed at care assistants providing care at home.

Aims

1. Improve the knowledge, understanding, attitudes, behaviours and clinical skills of care assistants providing end of life care at home by sharing Surrey hospices' expertise;

2. Enhance local partnership working and hospice education collaborations.

Method The hospices developed a three-day course comprising two taught days, a half day carers coaching session followed by group reflection. The course content is based on the five Priorities of Care with strong focus on the communication and practical skills required for end of life care.

Results A pilot programme was delivered in March 2018. Evaluation results were extremely positive with strong evidence that knowledge and skills gained were transferred into practice. Attendees indicated the course improved their knowledge and communication while the teaching style, coaching and reflection enhanced their understanding and performance.

Unfortunately, subsequent courses attracted low numbers with agencies reporting being unable to afford course costs (agreed at $£ 330 / 3$ days) and backfill. The hospices are seeking further Clinical Commissioning Group support and/or grant funding to continue offering the course and in addition, it will now be offered beyond domiciliary care to residential and care home staff as well.

\section{P-50 COLLABORATION AND NETWORKING: DEVELOPING THE PALLIATIVE MEDICINE SAS DOCTOR WORKFORCE IN THE NORTH WEST}

${ }^{1}$ Aruna Hodgson, ${ }^{2}$ David Waterman, ${ }^{3}$ Helen Bonwick. ' Health Education England, Liverpool, UK; ${ }^{2}$ Greater Manchester and Eastern Cheshire Strategic Clinical Network, Manchester, UK; ${ }^{3}$ Marie Curie Hospice Liverpool and Liverpool Heart and Chest Hospital., Liverpool, UK

\subsection{6/bmjspcare-2019-HUKNC.74}

Background The Palliative Medicine workforce is diverse, including consultants, SAS (staff grade, associate specialist and specialty) doctors, GPs and training grades. This project, funded by Greater Manchester and Eastern Cheshire Strategic Clinical Networks, was designed specifically to support the development of SAS doctors working in specialist palliative care in the region. It aimed to help address the challenge of ensuring that there are enough appropriately trained doctors to meet current and future service need.

Aims and methods of the project

- Mapping of numbers of doctors working in Palliative Medicine in SAS grade or similar posts across the region; 